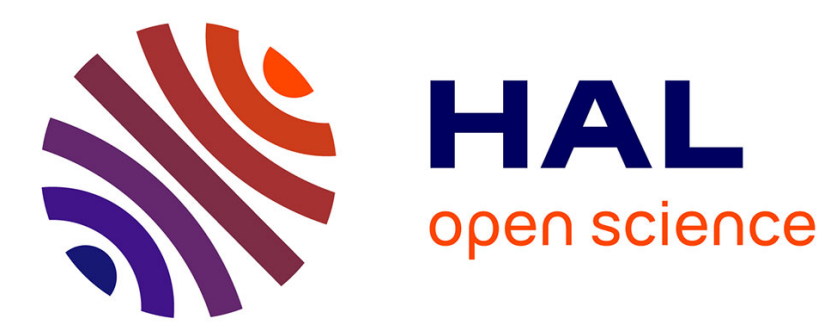

\title{
Theory Construction
}

Jean Sallantin, Stefano A. Cerri

\section{To cite this version:}

Jean Sallantin, Stefano A. Cerri. Theory Construction. Encyclopedia of the Sciences of Learning, Part 20, Springer, pp.3311-3314, 2012, 10.1007/978-1-4419-1428-6_60 . lirmm-00670584

\section{HAL Id: lirmm-00670584 https://hal-lirmm.ccsd.cnrs.fr/lirmm-00670584}

Submitted on 16 Feb 2012

HAL is a multi-disciplinary open access archive for the deposit and dissemination of scientific research documents, whether they are published or not. The documents may come from teaching and research institutions in France or abroad, or from public or private research centers.
L'archive ouverte pluridisciplinaire HAL, est destinée au dépôt et à la diffusion de documents scientifiques de niveau recherche, publiés ou non, émanant des établissements d'enseignement et de recherche français ou étrangers, des laboratoires publics ou privés. 


\section{Metadata of the chapter that will be visualized online}

\begin{tabular}{lll}
\hline Chapter Title & Theory Construction & \\
\hline Copyright Year & 2011 & \\
\hline Copyright Holder & Springer Science + Business Media, LLC \\
\hline \hline Corresponding Author & Family Name & Sallantin \\
& Particle & \\
& Given Name & Jean \\
& Suffix & \\
Division & LIRMM: Laboratory of Informatics, Robotics and Microelectronics \\
& Organization & University Montpellier2 \& CNRS \\
& Address & 161 rue Ada, 34095, Montpellier, Cedex 5, France \\
& Email & js@lirmm.fr \\
\hline Author & Family Name & Cerri \\
& Particle & \\
Given Name & Stefano A. \\
& Suffix & \\
& Division & LIRMM: Laboratory of Informatics, Robotics and Microelectronics \\
& Organization & University Montpellier2 \& CNRS \\
& Address & 161 rue Ada, 34095, Montpellier, Cedex 5, France \\
Email & cerri@lirmm.fr \\
\hline
\end{tabular}


-

(5)


$\mathbf{T}$

Jean Sallantin, Stefano A. Cerri

LIRMM: Laboratory of Informatics, Robotics and

Microelectronics, University Montpellier2 \& CNRS,

Montpellier, Cedex 5, France

\section{Synonyms}

8 Scientific discovery

\section{Definition}

Theory construction is a process, i.e., a set of state changes by an autonomous agent, or by an organism composed of several autonomous agents. In the first case, we may recall the approach of Pierce (1931) that considers three logical operations (inference rules) on a knowledge base, i.e., a set of propositions asserted to be valid: abduction, deduction, and induction. Abduction generates new hypotheses from which deduction derives predictions to be confirmed by experience. The confirmed hypotheses are structured by induction into laws of general validity. A similar way to describe the life cycle of theory construction within a single agent is to say that the real world asks the agent for a concrete solution in a single instance case, then the solution is abstracted in order to identify laws that are more general; finally the abstracted solution is applied to other classes of instances of the abstract problem, i.e., it is generalized. The interplay of these operations in one single autonomous (artificial) agent is widely modeled in the work on machine learning.

The second social scenario - communicating agents learning by exchanging messages - is less easily formalized but probably more realistic when describing human learning. In this article we give support to the conjecture that the process of construction of knowledge in science (theory construction or scientific discovery) and human learning is an interactive human process of a social nature that presents profound similarities and relations with each other so that we may profit from advances in one domain to infer properties of the other one and the reverse. In this approach we are strongly influenced by constructivism 39 (Piaget 1970) and social constructivism.

\section{Theoretical Background}

The previous century has been characterized by 42 a constructivist approach to science (Zalta 2011). Knowl- 43 edge construction in any science was strictly associated to 44 proof and validation (Popper 1959). Obviously, proof and 45 validation in history, for instance, is not the same as in 46 mathematics and, in turn, not the same as in physics or 47 biology. Nevertheless, all these proof-and-validation pro- 48 cesses require to possess a critical mind as well as to 49 exercise a critical approach knowing that proofs and val- 50 idations have to be accepted by others. Theory construction 51 is then the result of a social game that enables the historical 52 development of newborn theories that progressively focus 53 their own validation domain. In more general terms, the 54 scientific activity is considered as a social activity 55 influenced, as all the other ones, by pressures of the con- 56 temporaneous leading powers (Kuhn 1962; Latour 1987). 57

The end of the previous century is marked by an 58 evolution of reductionism. Reductionism can either mean 59 (a) an approach to understanding the nature of complex 60 things by reducing them to the interactions of their parts 61 or to simpler things or (b) a philosophical position that 62 a complex system is nothing but the sum of its parts, and 63 that an account of it can be reduced to accounts of indi- 64 vidual constituents. Problem solving is not considered 65 anymore just as consisting of decomposing each problem 66 into a finite set of subproblems and composing the solu- 67 tions. Rather, the holistic, situated approach to problem 68 solving requires one to integrate (or make interoperable) 69 the partial results validated by different scientific disci- 70 plines. Reductionism and holism seem today complemen- 71 tary approaches. For instance, understanding and 72 Au3 forecasting phenomena related to the global warming 73 problem requires to consider the planet and model simul- 74 taneously, for example, their physical, chemical, biological, 75 and social properties. A regulation rule influencing human 76 Au4 behavior acts modifying the actors thus the observed 77 system. According to the pioneer ecologist Francesco 78 Di Castri, for instance (Di Castri and Hadley 1988), 79 
one of the major scientific bottlenecks to natura resource management was the lack of a holistic approach bridging ecology (in fact, according to his views, social ecology with a strong emphasis on human impact) and the natural sciences. We are facing what people call a complex system with feedback. From a practical viewpoint, reductionism supports human learning by disciplinary subjects and toy problems, while a holistic view supports learning by solving realistic inter-, trans-, and multidisciplinary problems.

\section{Important Scientific Research and Open Questions}

Scientific knowledge is built and communicated by means of interactions among scientists and between scientists and all other human beings. Several interaction communities are formed and dissolved each having properties that are different one from another. A scientist does not process his/her theories alone, but rather he/she is guided by critics of his/her pairs on a scientific production offered as a contribution to the solution of problems identified within a scientific context where publications already exist. A well-trained researcher should be able to enact successfully a problem-solving process on old and new problems within a scope limited by the discipline of expertise. The training requires exercise but training and practice are intertwined all life long, not separated in temporal phases, so that we may treat scientists as lifelong students and teachers at the same time.

The interactive view does not assume that each of the interacting partners have the same knowledge, language, goals, plans, strategies, tactics, intentions, preconceptions, assumptions, misconceptions, etc. In order to hopefully converge to an agreement, arguments and counterarguments are discussed and exemplified in a social, interactive negotiation. Communities exchange messages according to patterns and rules that historically have been studied in sociolinguistics: pragmatics, which is the science of understanding the relations between messages and the state of the actors producing and receiving those messages, and rhetoric, which is the art of convincing a partner about an argument or evoking emotions into a partner, are the disciplines that deal best with human interaction. In the most interesting case, the rhetoric game of interacting for negotiating meaning occurs between and among actors belonging to different viewpoints/disciplines, thus offering inter-, multi-, and transdisciplinary scenarios of collective intelligence. Recently, emotions and personality traits have entered the scene as a mean to understand individual intelligence; thus we expect them also to be at the core of phenomena of collective intelligence.
Formal theories of interactive learning study different 130 approaches of knowledge construction and their effective- 131 ness. It is usually hard to say that one approach is correct 132 and the other ones are wrong; often it is the case that they 133 are complementary. Let us consider foreign language 134 learning by practice: after a while, the learner's perfor- 135 mance improves and his/her mistakes diminish. This 136 learning is accelerated if the instructor confirms (or not) 137 the correctness of his/her sentence, or either when the 138 instructor shows the apprentice the incorrectness of 139 a grammatical form by showing a counter example. Such 140 training by practice is also common in learning of sports or 141 in learning of artistic skills when the trainee is required to 142 adopt complex practices without necessarily justifying 143 them as theories. Any learning needs practice: the trainer 144 should define the exercises adequate for the learner to 145 untie the body and the mind. Similarly, the researcher's 146 work requires a practice to learn how to be creative. But 147 practice and supervised learning without creativity and 148 autonomous rational thinking seem to concern only 149 a minor part of the complex knowledge and skills required 150 for coping with realistic problems.

Where does creativity come from? Sometimes it 152 emerges from a coincidence; often it is the fruit of 153 a surprise (unexpected event) assuming the mind is well 154 prepared to that event. The history of sciences is full of 155 discoveries emerging from chance, manipulation errors, 156 even from the innocent viewpoint expressed by a novice. 157 Such serendipitous events look quite similar to learning as 158 a side effect of interaction: something that happens even if 159 we can neither forecast its occurrence nor explain its 160 origins.

We will reinterpret multi-, inter-, and transdisci- 162 plinarity as modalities of collective behavior of the social 163 game of theory construction that we claim to be similar to 164 human learning. Assume a "service-oriented view" of such 165 a social interaction: the one actor produces a statement and 166 the other one consumes it, either for progressing in his/her 167 own scientific construction, or for demonstrating/refuting 168 the validity of the proposed statement. Under the hypoth- 169 esis that the two actors come from different disciplines (or 170 sub-domains of knowledge) one may have several com- 171 posite situations - interaction patterns - that explain the 172 nature and complexity of the holistic view previously 173 identified to be a foundation of current scientific progress 174 as well as modern learning processes.

175

At the basis of each of those situations there is the fact 176 that "Real-world problems may not respect discipline 177 boundaries" (Popper 1959) while scientific communities 178 are made of actors that mainly master a single discipline, 179 including the lexicon and the methods. Here is the crucial 180 
challenge for the future of science as well as innovation and, simultaneously, human learning: How to exploit disciplinary convictions, viewpoints, rules, and jargon when many of them should interact synergically. Hereafter is a simple, though significant preliminary classification that adopts the above identified classification criteria.

Multidisciplinarity: each actor uses statements proved by his/her (multidisciplinary) community in his/her own problem's statement and argumentation.

Interdisciplinarity: each actor exploits in her/his proof statements proved by another community. The principle of interdisciplinarity is to admit as axioms some results proved by other communities that one cannot prove by himself. An interdisciplinary approach is required when there is no discipline omniscient and omnipotent able to solve the problem without intervention from others.

Transdisciplinarity: actors propose some hypothetical statements to other communities that trigger inter- or multidisciplinary work (Piaget 1970).

Each of these interaction scenarios may be mapped to many concrete situations (called also business processes) of theory construction and scientific discovery, but also of technological innovation. In human learning, similarly, the game of collective construction of knowledge is very clearly influenced by synergies between and among actors each representing different disciplines, viewpoints, and interests.

Finally, the interactive construction of scientific theories can be viewed as an activity intertwined with two kinds of learning: one is supervised by the teacher or master and implies the acquisition of practical skills; the 211 other is unsupervised as it is concerned with the commu- 212 nication of knowledge in the form of documents that have 213 to be evaluated by pairs.

Since both the process of creative discovery in science 215 and learning in all its facets present those quite similar 216 properties, we may assume that they are related to each 217 other, so that advances in understanding each of the two 218 may be profitable for the other one and the reverse. $\quad 219$

\section{Cross References}

220

- Abductive Reasoning

- Advanced Learning Technologies 222

- Learning as a Side Effect

- Networked Communities

\section{References}

di Castri, F., \& Hadley, M. (1988). Enhancing the credibility of ecology: 226 Interacting along and across hierarchical scales. GeoJournal, 17(1), 227 $5-35$.

Kuhn, T. S. (1962). The structure of scientific revolutions. Chicago: Univer- 229 sity of Chicago Press.

Latour, B. (1987). Science in action. Cambridge, MA: Harvard University 231 Press.

Peirce, C. S. (1931). Collected papers of Charles Sanders Peirce (1839- 233 1914). Cambridge, MA: The Belknap Press/Harvard University Press. 234

Piaget, J. (1970). L'épistémologie génétique. Paris: Presses universitaires de 235 France.

Popper, K. (1959). The logic of scientific discovery. London: Hutchinson. 237

Zalta, E. N. (2011). (Principal Editor) Stanford encyclopedia of philoso- 238 phy. Vienna Circle. http://plato.stanford.edu/entries/vienna-circle/ 239 
Author Query Form

Encyclopedia of the Sciences of Learning

Chapter No: 60

\begin{tabular}{|l|l|l|}
\hline Query Refs. & Details Required & Author's response \\
\hline AU1 & Kindly confirm the author affiliation & \\
\hline AU2 & $\begin{array}{l}\text { Please check if edit to sentence starting "In this } \\
\text { article we give..." is okay. }\end{array}$ & $\begin{array}{l}\text { Please check if the edit made to the sentence } \\
\text { starting "For instance, understanding and..." is } \\
\text { okay. }\end{array}$ \\
\hline AU3 & $\begin{array}{l}\text { In the sentence starting "A regulation rule influen- } \\
\text { cing..." please check the phrase "acts modifying } \\
\text { the actors" for sense. }\end{array}$ & \\
\hline AU4
\end{tabular}

